\title{
RESEARCH PAPER RP1153
}

Part of Journal of Research of the National Bureau of Standards, Volume 21, December 1938

\section{EXPANSION EFFECTS ON THE INVERSION OF SILICA CRYSTALS IN CERTAIN DEVITRIFIED GLASSES}

\author{
By Arthur Q. Tool and James B. Saunders
}

\section{ABSTRACT}

Expansion curves are presented which show the inversion effects of the cristobalite, tridymite, and quartz that were present in a devitrified glass having a relatively high silica content. These results agree in practically every respect with results presented in a previous paper and obtained from the exothermic and endothermic effects caused by the same inversions. So far as these results are concerned with the nature and changes of inversion effects as tridymite is developed from cristobalite and quartz, they substantiate the previously suggested possibility that there are, at room temperature, two or more forms of tridymite instead of only one, such as has been generally supposed.

\section{CONTENTS}

I. Introduction _... 773

II. Method of measurement $\ldots \ldots \ldots$

III. Results

IV. Conclusion_....... 778

\section{INTRODUCTION}

This paper deals with the expansion efiects of inversion that were obtained on some of the samples discussed in a previous paper ${ }^{1}$ which describes the heat effects and some of the characteristics of the crystals found in a devitrified borosilicate glass having a rather high silica content. A description of the glass and fuller details concerning the heat treatments causing its devitrification will be found in that paper. The chief purpose in obtaining the expansion data was the corroboration of previously described results on the progressive changes in the characteristics of the "prompt" inversions of the crystalline silica. Such changes developed as the various "sluggish" inversions proceeded at treating temperatures in the devitrification range of the glass.

\section{METHOD OF MEASUREMENT}

The expansion data (curves) were procured by means of the interferometric method and the apparatus used has been described in previous papers. ${ }^{2}$ The test samples (three pyramidal spacers) were, however, smaller (height, $1.78 \mathrm{~mm}$ in one case) than usual because

1 Tool and Insley, J. Research NBS 21, 743 (1938) RP 1152.

${ }^{2}$ Tool, Lloyd, and Merritt, BS J. Research 5, 627 (1930) RP219. Saunders and Tool, BS J. Research 11, 799 (1933) R P626. 
larger pyramids were likely to crack during the repeated heatings and coolings required by a series of tests. While this reduction in size made long series of tests possible, it materially reduced the precision of the measurements. This, however, was no great handicap because the expansion changes sought were ordinarily much greater than the uncertainties in the measurements. Moreover, the principal purpose was to locate inversion effects rather than to make highly accurate expansivity measurements. In general, the samples used in the expansion tests were subjected to devitrifying treatments along with the corresponding samples employed in the heating and cooling curve tests mentioned above.

Interferometer plates of fused silica were used in these expansivity tests because the measurements were carried to relatively high temperatures. Moreover, it is evident that it would be impossible to match the extremely variable expansion of the devitrified samples with that of any material suitable for these plates, although such a match is very desirable in making precise measurements on ordinary samples. The lower interferometer plate on which the pyramidal spacers rested was so constructed and calibrated that it served as an interferometric thermometer for determining the temperature changes during the required heatings and coolings of the tests. When properly assembled and mounted in the test furnace and observed through a viewing apparatus, the interferometer system presented two sets of fringes separated by a narrow boundary. As the temperature changed, the passage of the fringes over fiducial points was recorded by means of a chronograph. From the resulting record the changes in temperature and the corresponding length changes per unit length of sample could be computed. The number of fringes was such that the approximate average expansivity over small temperature intervals never exceeding $5^{\circ} \mathrm{C}$ could easily be determined for each such interval in the range between room temperature and $625^{\circ} \mathrm{C}$. In obtaining these data the heating rate throughout this range was approximately $3.5^{\circ} \mathrm{C}$ per minute.

\section{RESULTS}

The results presented here include only those obtained on two samples. These were numbered 1 and 8 in the first paper cited above. The first of these samples was treated for 25 days at $725^{\circ}$ $\mathrm{C}$, after which it contained considerable cristobalite and tridymite plates, some wedge-shaped twins of the latter, and a little quartz. A petrographic examination of this sample indicated that cristobalite was probably the main crystalline phase, but the thermal expansion, as well as the other heat effects, seem to show that tridymite was predominant. That is, the expansion curve ( $B$, fig. 1$)$ indicates relatively large inversion effects near $115^{\circ}$ and $150^{\circ} \mathrm{C}$ in the tridymite range and another effect between $500^{\circ}$ and $600^{\circ} \mathrm{C}$. The latter is probably a composite of "rapid" expansion effects in both the residual glass and the quartz.

Curves $A$ and $A^{\prime}$ in figure 1 are the expansion and contraction (heating and cooling) curves of the original glass, and a comparison of these curves with curve $B$ shows the great change in the expansion caused by the devitrification. The change in the trend of curve $A$ near $450^{\circ} \mathrm{C}$ indicates that the unannealed glass was entering the 
annealing range at these temperatures, and the rise starting near $550^{\circ}$ $\mathrm{C}$ corresponds to the beginning of the rapid-expansion range of this glass previous to its devitrification. The drop to curve $A^{\prime}$ at $625^{\circ}$ $\mathrm{C}$, where the glass was held for a time preparatory to starting the cooling curve, corresponds not to a deformation but to an actual though relatively slow contraction which this type of glass invariably shows in this temperature range. In the case of the devitrified sample, the beginning of the rapid-expansion range of the residual glass (curve $B$ ) apparently occurs near $470^{\circ} \mathrm{C}$, and there is some indication of a quartz effect just above $550^{\circ} \mathrm{C}$. The rate of deformation of the devit-

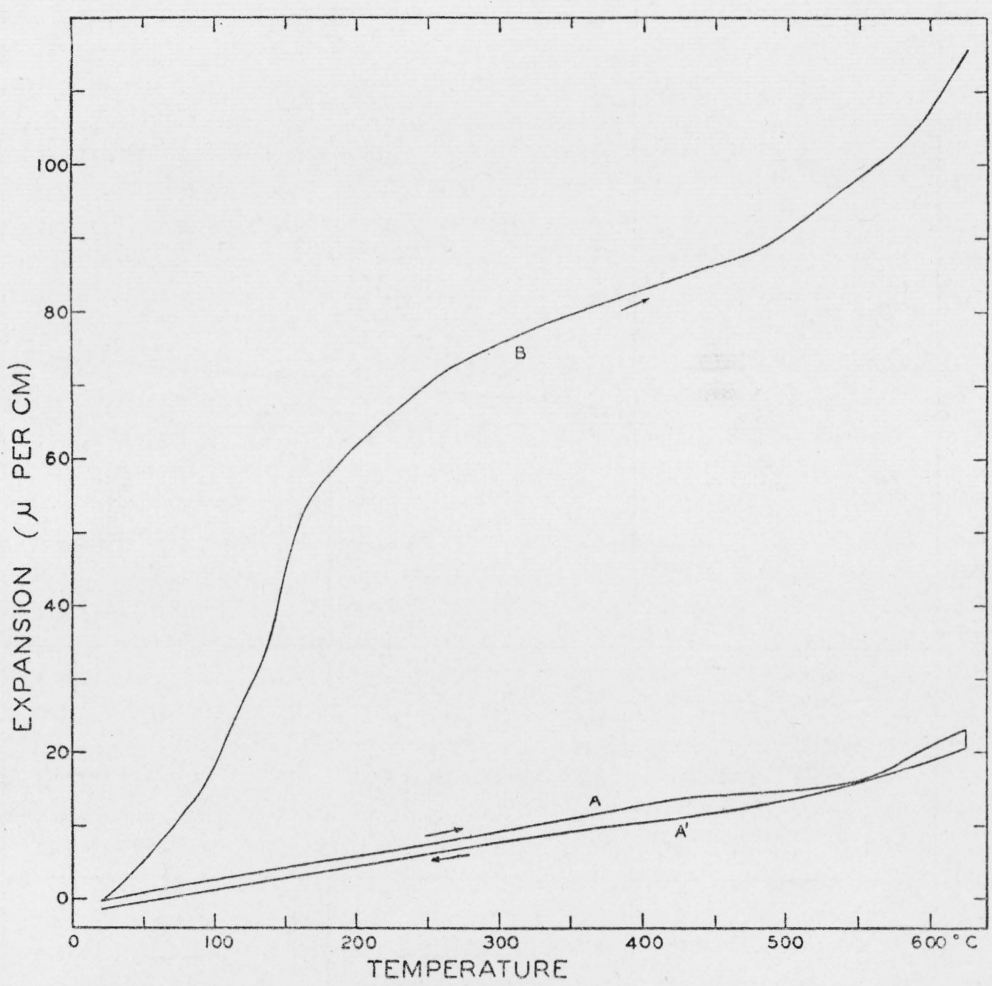

Figure 1.-Expansion curves of devitrified $(B)$ and undevitrified $\left(A\right.$ and $\left.A^{\prime}\right)$ samples. The change in expansion was caused by the devitrification of a borosilicate glass containing a relatively high percentage of silica.

rified glass was appreciable at temperatures above $600^{\circ} \mathrm{C}$ and this shows that devitrification greatly softened the material.

The first eight of the series of curves in figure 2 show the changes in the apparent expansivity with temperature (between $50^{\circ}$ and $300^{\circ} \mathrm{C}$ ) after the glass had been subjected to various periods (ranging from 3 to 313 days) of devitrifying treatment at $800^{\circ} \mathrm{C}$. After 3 days of treatment the cristobalite effect near $200^{\circ} \mathrm{C}$ was very large, and there was some indication that a tridymite effect near $150^{\circ} \mathrm{C}$ was developing. After the sixth and seventh days the cristobalite effect had practically disappeared, and it was practically nonexistent after the ninth day. From the sixth and through the twelfth days the 
intermediate tridymite effect near $150^{\circ} \mathrm{C}$, being quite large, was predominant, but by the eighteenth day it had yielded this dominance to the tridymite effect which had been slowly developing near $100^{\circ} \mathrm{C}$ since the sixth day of treatment. After the thirtieth day the tridymite effect near $100^{\circ} \mathrm{C}$ was practically the only one remaining and it had also practically disappeared when the treatment totaled 313 days

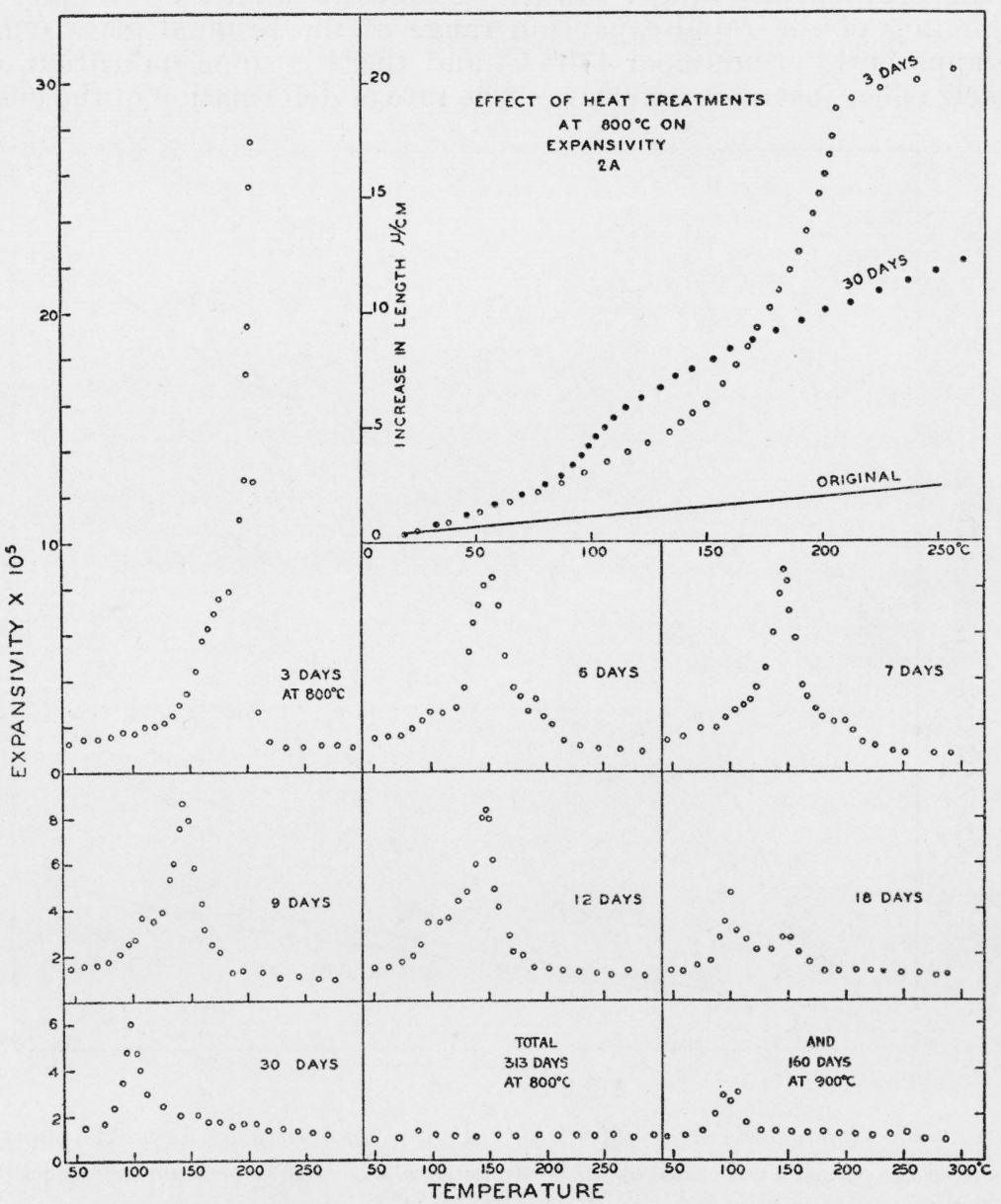

FiguRe 2.-Approximate apparent expansivities of the devitrified glass after treatments of various duration at $800^{\circ} \mathrm{C}$.

These curves show the change in apparent erpansivity with temperature and the progressive change in the inversion effects as the duration of the heat treatment was inereased. Figure $2 A$ presents some of the expansion curves from which the apparent expansivities were computed.

because the tridymite had been transformed into quartz. Throughout most of the time that the intermediate tridymite effect was dominant, tridymite plates appeared to be the predominant crystalline phase; but these plates were displaced by wedge-shaped tridymite twins at about the time that the effect near $100^{\circ} \mathrm{C}$ became dominant.

The results derived from expansion curves indicate that as the duration of the heat treatment increased the cristobalite and tridymite 
effects, respectively, disappeared and developed sooner than the corresponding exothermic effects derived from cooling curves obtained on the same sample, No. 8, as described in a previous paper. (Tool and Insley, footnote 1.) These differences appear because the expansion samples were selected from parts of No. 8 which were uniformly devitrified and in consequence practically free from clear glass at the end of the first 3 days of treatment, whereas the samples used in obtaining the exothermic effects were representative of the whole of No. 8 .

Figure $2(A)$ presents two examples of the expansion curves from which the approximate expansivities shown by the curves in figure 2

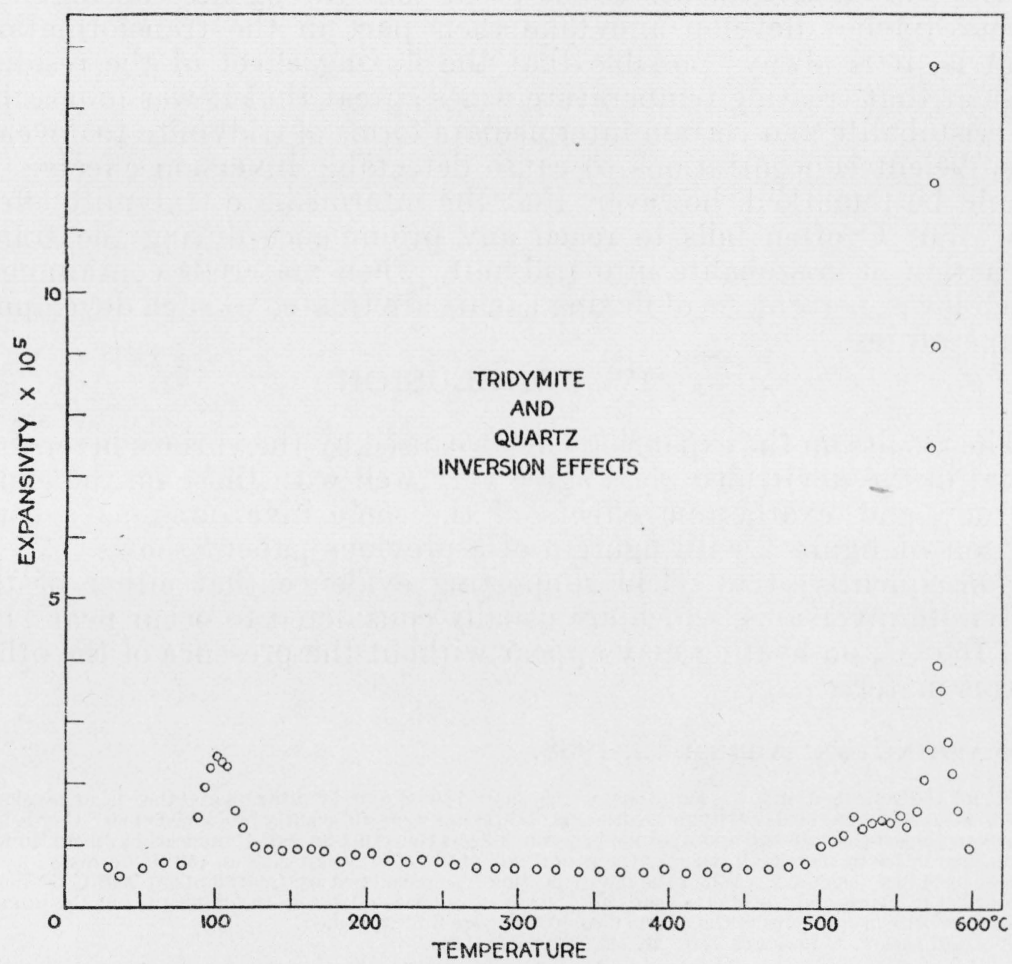

Frgure 3.-Tridymite and quartz inversion effects.

This curve was obtained after a heat treatment of 55 days at $800^{\circ} \mathrm{C}$. The small effect beginning at about $470^{\circ} \mathrm{C}$ and just preceding the quartz effect was caused chiefly by the normal increase in the apparent expansivity of the residual glass in this range, although adjustments preliminary to the quartz inversion probably add to this increase.

were computed. For comparison the expansion curve of the original glass is also included.

The curve presented in figure 3 shows the apparent expansivities of sample 8 after it had been treated for 55 days at $800^{\circ}$ C. Two inversion effects were found at this time, the tridymite effect near $100^{\circ} \mathrm{C}$ and the quartz effect near $575^{\circ} \mathrm{C}$. After the 313th day of treatment the quartz effect was more than six times as large as that shown here, and the tridymite effect had practically disappeared, as shown in figure 2. To reduce this quartz to tridymite the treating temperature was raised to $900^{\circ} \mathrm{C}$ and after 160 days the completion 
of this reduction was being approached. Tests made at intervals during this treatment showed no indications of the cristobalite and intermediate tridymite effects, but the tridymite effect near $100^{\circ} \mathrm{C}$ soon appeared and grew slowly as the quartz effect diminished. The effect obtained near $100^{\circ} \mathrm{C}$ as the result of a test following the 160 th day of treatment at $900^{\circ} \mathrm{C}$ is shown in the last of the series of curves in figure 2 .

The fact that the cristobalite and intermediate tridymite effects were not detected during the development of the effect near $100^{\circ} \mathrm{C}$ as the quartz was transformed into tridymite wedge-shaped twins ${ }^{3}$ by the $900^{\circ} \mathrm{C}$ treatments is not proof that the agents causing these effects did not develop and take their part in the transformation. That is, it is always possible that the fluxing effect of the residual glass at that treating temperature was so great that it was impossible for cristobalite and certain intermediate forms of tridymite to develop in sufficient concentrations to cause detectable inversion effects. It should be remarked, however, that the intermediate tridymite effect near $150^{\circ} \mathrm{C}$ often fails to reach any prominence during the transformation of cristobalite into tridymite when materials containing a much lower percentage of fluxing agents are treated at such developing temperatures.

\section{CONCLUSION}

The results on the expansion effects caused by the various inversions found in the devitrified glass agree very well with those on the endothermic and exothermic effects of the same inversions, as a comparison of figure 2 with figure 6 of a previous paper ${ }^{4}$ shows.

Consequently, they yield supporting evidence that either of the tridymite inversions, which are usually considered to occur near $117^{\circ}$ and $160^{\circ} \mathrm{C}$, on heating may appear without the presence of the other in this material.

Washington, August 19, 1938.

3 During the investigation it was found that wedge-shaped twins of tridymite replaced the earlier developed tridymite plates when the devitrifying treatments of this glass were sufficiently prolonged at $800^{\circ} \mathrm{C} \mathrm{or} \mathrm{below}$. Moreover, the exothermic and endothermic inversion effects centering on $100^{\circ} \mathrm{C}$ increased in magnitude as the number of twins increased, whereas the magnitude of the effects centering on $150^{\circ} \mathrm{C}$ decreased as the number of plates decreased. When the devitrification was developed by treatments at $900^{\circ} \mathrm{C}$ or above, the number of plates and the effects near $150^{\circ} \mathrm{C}$ were at all times relatively insignificant, but the number of twins and the prominence of the effects near $100^{\circ} \mathrm{C}$ were undiminished.

Tool and Insley, J. Research NBS 21, 743 (1938) RP 1152. 